\title{
Psychogenic nonepileptic seizures and psychogenic movement disorders: two sides of the same coin?
}

\author{
Crises não-epilépticas psicogênicas e distúrbios do movimento psicogênicos: dois lados \\ da mesma moeda?
}

Luciano De Paola ${ }^{1}$, Renato L. Marchetti ${ }^{2}$, Hélio Afonso Ghizoni Teive ${ }^{3}$, W. Curt LaFrance-Jr. ${ }^{4}$

\begin{abstract}
Psychogenic nonepileptic seizures (PNES) and psychogenic movement disorders (PMD) are commonly seen in Neurology practice and are categorized in the DSM-5 as functional neurological disorders/conversion disorders. This review encompasses historical and epidemiological data, clinical aspects, diagnostic criteria, treatment and prognosis of these rather challenging and often neglected patients. As a group they have puzzled generations of neurologists and psychiatrists and in some ways continue to do so, perhaps embodying and justifying the ultimate and necessary link between these specialties.
\end{abstract}

Keywords: psychogenic nonepileptic seizures, psychogenic movement disorders, conversion disorder, hysteria.

\section{RESUMO}

Crises não-epilépticas psicogênicas (CNEP) e distúrbios do movimento psicogênicos (DMP) são comuns na prática e na atualidade são melhor categorizados no DSM-V como distúrbios neurológicos funcionais/desordens de conversão. Esta revisão enfatiza os principais dados históricos, epidemiológicos, clínicos, critérios diagnósticos, tratamento e o prognóstico destes pacientes, frequentemente negligenciados e desafiadores, os quais, como um grupo, tem intrigado gerações de neurologistas e psiquiatras, caracterizando, de forma justificada o elo definitivo entre estas especialidades.

Palavras-chave: crises não-epilépticas psicogênicas, distúrbios do movimento psicogênicos, distúrbio conversivo, histeria.

In the medical sciences, a diagnosis is established when a level of certainty regarding the nature of a condition is achieved. Psychogenic nonepileptic seizures (PNES) and psychogenic movement disorders (PMD) share a slightly less linear diagnostic route. Historically, making a conversion diagnosis required ruling out the originally considered medical diagnosis, i.e., it is neither epilepsy, nor a neurogenic movement disorder. Only then a non-neurologic (in the sense of not resulting from epileptogenic or known motor circuitry imbalance) condition is suspected and raised to the level of diagnosis ${ }^{1}$. This kind of diagnosis has intrigued generations of physicians and spared no culture, gender or age. A diversity of symptoms, including motor, sensory, cognitive, and/or behavior symptoms are present in these presentations. Patients with PNES or PMD frequently are misdiagnosed as having their initial suspected neurological diseases, and ultimately pose a diagnostic and treatment challenge to many clinicians. Interestingly, it was perhaps this varied presentation that has captured the attention of many professionals through the centuries and lead to the construction and recognition of a very particular diagnosis. Two rather advanced historic civilizations, Egyptians first, and then the Greeks, posited that a displaced hystera (womb), and the consequent suffocation that it produced, was the source of choking, mutism, paralysis and fainting ${ }^{1}$. Hysteria, a natural development on this concept, was claimed as an explanation for similar phenomena in women and reached almost epidemic proportions in the late $19^{\text {th }}$ century. By then, French

${ }^{1}$ Serviço de Neurologia, Hospital de Clínicas, Universidade Federal do Paraná, Curitiba PR, Brazil;

${ }^{2}$ Instituto de Psiquiatria, Hospital das Clínicas, Faculdade de Medicina, Universidade de São Paulo, Sao Paulo SP, Brazil;

${ }^{3}$ Departamento de Transtornos do Movimento, Hospital de Clínicas, Universidade Federal do Paraná, Curitiba PR, Brazil;

${ }^{4}$ Psychiatry and Neurology Departments, Brown Medical School, Rhode Island Hospital, Providence RI, USA.

Correspondence: Luciano de Paola; Rua Francisco Torres, 528 / 191; 80060-130 Curitiba PR, Brasil;. E-mail: luciano.depaola@gmail.com

Conflict of interest: There is no conflict of interest to declare.

Disclosures: Dr. LaFrance receives editor’s royalties for Gates and Rowan's Nonepileptic Seizures, $3^{\text {rd }}$ Edition, Cambridge University Press, ${ }^{\circ} 2010$.

Received 01 June 2014; Accepted 25 June 2014. 


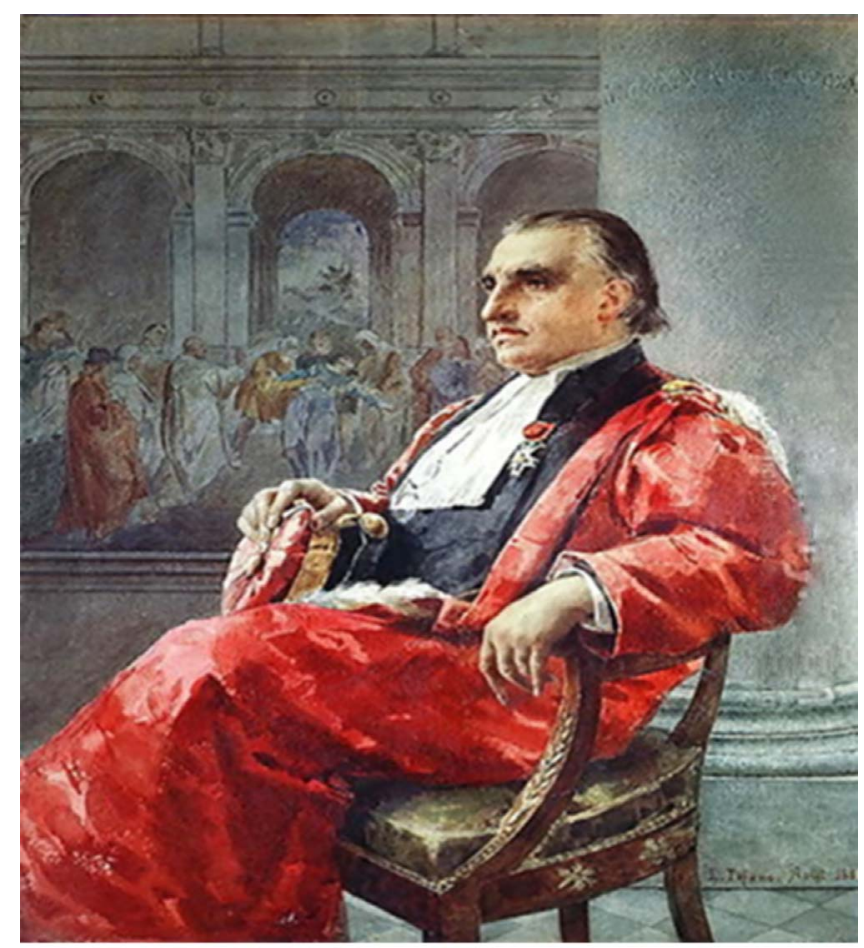

(www.1st-art-gallery.com), Eduardo Tofano, August, 1881.

Figure 1. Professor Jean-Martin Charcot (1825-1893)

and British women displayed a rather elevated prevalence of hysteria, which was associated with the work of Jean Martin Charcot (Figure 1). His harshest critics proposed that he created this disease and gained profit from it ${ }^{2}$. From a contemporary perspective, it may be tempting to scrutinize the dramatic performances of some of Charcot's young female patients, who may have been prone to suggestibility of the famous professor's hypnosis techniques'. It was due to Charcot's astute clinical observations, however, that hysteria moved from an almost gynecological disease to a neurologically conceived condition. Regarding male hysteria, Charcot followed after Galen (who suggested that retained sperm could lead to male hysteria) and later Charles LePois, Briquet and Savill, to offer a full description of hysteria in men (Charcot even mentioned epidemiological data, suggesting that $5 \%$ of his hysterical patients were male) $)^{2}$. The "shell-shock" syndrome described in the World War I trenches consubstantiated the concept of "male hysteria". Hysteria, in all fairness, respects no gender, i.e. somatoform symptoms are present in women and $\mathrm{men}^{3}$. In spite of the controversy produced by historical reflections and opinions on Charcot's motives and deep involvement with the field of hysteria, these patients finally came to light in a somewhat "medically organized" fashion and certainly inspired very prestigious minds eager to take this diagnosis to a different level of understanding ${ }^{2}$. Sigmund Freud spent four months at the Salpêtrière between October, 1885 and February, 1886 and his enthusiasm for neurosis and psychology was certainly the product of this stay ${ }^{2}$. His attention is observed in that over
100 out of the 3000 books in Freud's private library were dedicated to hysteria and hypnosis, and all were authored by either Charcot himself or one of the French professor's direct pupils ${ }^{2}$. Just prior to Charcot's death, Charcot acknowledged that he had been mistaken and that hysteria was truthfully a psychiatric disease. By then, Alienism was in the process of becoming the modern psychiatry ${ }^{2}$. Hysteria fell into academic disgrace, raising derogatory connotations and the word itself was removed to the lay domain. The condition was renamed by Babinski to pithiatism; the number of publications on hysteria decreased significantly and at a given point it has been considered an excuse for lack of medical knowledge or poor diagnostic skills. Renowned publications such as the British Medical Journal released papers in the 60's reflecting the thoughts of authors calling hysteria the "disguise for ignorance and fertile source for clinical errors". This assumption of diagnostic ignorance was proven incorrect with the advent of advanced diagnostic techniques. In the 1970's and 1980's, the birth of epilepsy monitoring units and the technology to document patients and their events for long periods of time surfaced literally all sorts of epilepsy "imitators", including PNES $^{5}$. Some of them, such as paroxysmal, transitory, tremor-like or tic-like episodes without loss of consciousness can be interpreted as either PNES or PMD, depending on the setting and context that they are disclosed. What was "hysteria" in the past, today has different nomenclatures (e.g. medically unexplained symptoms, somatoform disorders, etc.). As any practicing clinician knows, the disorder clearly still presents itself in the $21^{\text {st }}$ century in the symptoms and semiology of a substantial percentage of patients in both epilepsy and movement disorders clinics. Conversion symptoms very infrequently can be a sole phenomenon, however, the vast majority of patients have a psychiatric comorbidity and/or a significant stressor, either recently or remotely. In this paper, the authors intend to review and explore both commonalities, as well as, unique expressions that are present in PNES and PMD. We will systematically discuss PNES and PMD as independent conditions that might share similar natures and etiologies, and hopefully, offer a systematic approach to general management and treatment.

\section{FUNCTIONAL NEUROLOGICAL DISORDERS (CONVERSION DISORDERS)}

Psychogenic symptoms, or, functional symptoms, are commonly seen in clinical practice and are estimated to represent $10 \%$ of all medical complaints ${ }^{6,7,8,9}$. They are common in neurology, accounting for 10 to $33 \%$ of patient visits to a neurologist and $9 \%$ of inpatient neurology admissions ${ }^{6-8}$. The importance of the exam in conversion disorder (CD) has been underscored with the inclusion of the presence of these signs in the diagnostic criteria of CD in DSM- $5^{10}$. Several neuro- 
logical symptoms can have psychogenic mechanisms underlying their presentation, including paralysis, sensory loss, blindness, astasia-abasia, amnesia, PNES and PMD $^{6-9}$. Daum et al. performed a systematic and narrative review about the value of "positive" clinical signs for weakness, sensory and gait disorders in conversion disorder ${ }^{11}$. The authors did not study signs for PNES. They concluded that clinical signs for motor, sensory and gait functional neurological symptoms are numerous, and 14 have been validated ( 7 motor, 5 sensory, and 2 gait related $)^{11}$. Among positive signs of functional motor, sensory and gait disorders, Hoover sign, abductor sign, abductor finger sign, co-contraction, midline splitting, non-anatomical sensory loss, dragging monoplegic gait, and chair test have been validated ${ }^{11}$. Daum et al. also reviewed non-validated, positive signs of functional disorders, which included non-pyramidal weakness, absent pronator drift, arm drop test, Barré test, platysme sign, Babinski trunk-thigh test, Bowlus-Currier test, excessive slowness, fluctuation, psychogenic Romberg test, walking on ice, sudden knee buckling, astasia-abasia, and expressive behavior ${ }^{11}$. Lombardi et al. published on a sign to detect unilateral upper extremity non-organic paresis, the elbow flex-ex ${ }^{12}$. This test is useful in differentiating between functional and nonneurologic arm paresis ${ }^{12}$.

Functional (psychogenic) neurological disorders/CD have been described as hysteria, somatization disorder, nonorganic disorders and medically unexplained symptoms ${ }^{7,11,13}$. Stone et al., evaluated 1144 new neurology outpatients with symptoms "unexplained by organic disease" ${ }^{14}$. The most common diagnoses were neurological disease but with symptoms unexplained by this condition (26\%), headache disorders $(26 \%)$ and conversion symptoms (motor, sensory or non-epileptic seizures) $(18 \%)^{14}$. At follow-up, only $0.4 \%$ of 1030 patients had an organic disease diagnosis confirmed. The authors concluded that one-third of new neurology outpatients were diagnosed as having symptoms "unexplained by organic disease" 14 .

Structural neuroimaging does not reveal a "conversion lesion”. Unexplained neurological symptoms, however, are being studied using functional MRI. In general, studies using this technique have demonstrated that active inhibition in the orbitofrontal cortex and cingulate gyrus may be implicated in functional disorders ${ }^{15}$. Different subtypes of FNDs are shown in Figure 2. The most prevalent psychogenic conditions in practical clinical neurology are generally PNES and $\mathrm{PMD}^{6,8}$.

\section{PSYCHOGENIC NON-EPILEPTIC SEIZURES}

Non-epileptic seizures (NES) are characterized by paroxysmal, involuntary, usually time-limited alterations in motor and/or sensory function, level of consciousness and behavior that may resemble epileptic seizures (ES), but are

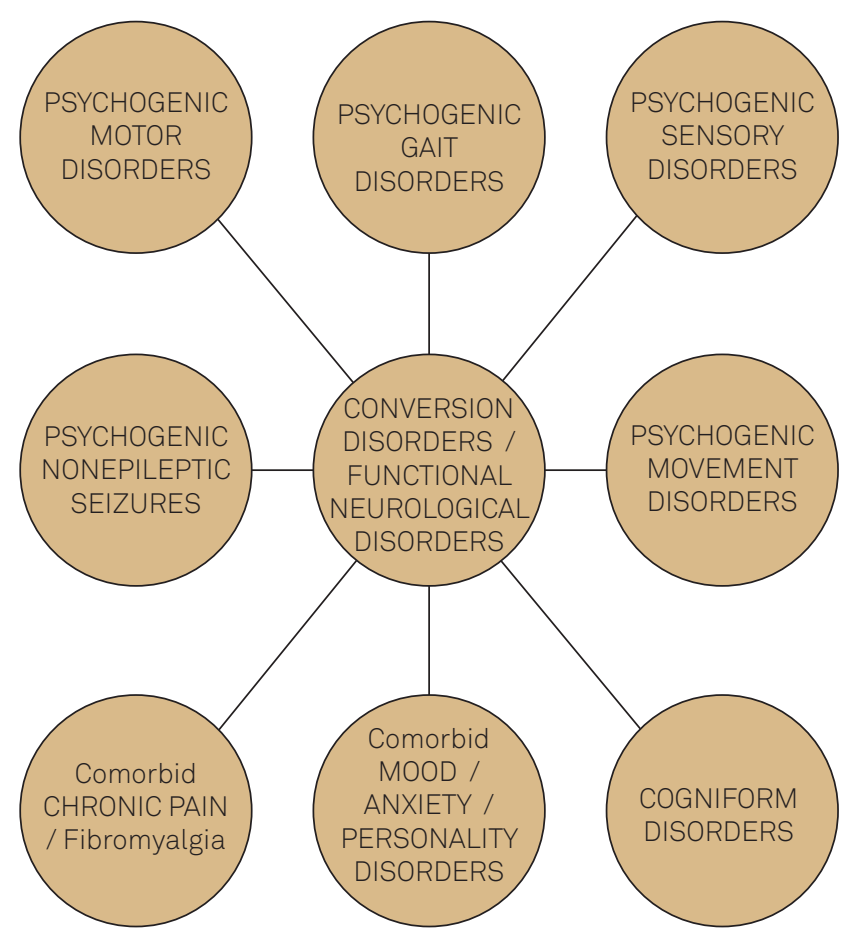

Figure 2. Conversion Disorders Functional Neurological Disorders - Subtypes \& Comorbidities.

not caused by epileptic discharges ${ }^{16}$. They can be of physiologic or psychogenic (PNES) origin. The most common causes of physiologic non-epileptic events, such as syncope $^{16}$, do not pose a significant problem to differential diagnosis when video-electroencephalography (VEEG) monitoring is used ${ }^{16}$. A long list of mental disorders may present as $\mathrm{PNES}^{16}$. Patients typically present with episodes characterized by disrupted consciousness or motor/sensory manifestations. Although deficits and symptoms can be produced voluntarily, as in factitious disorders and malingering (found in a small percentage of individuals with neurologic presentations), psychogenic disorder presentations are involuntary (unconsciously produced), as in patients with somatoform disorders and dissociative disorders ${ }^{16}$. Several putative psychological mechanisms of PNES have been conceptualized and described ${ }^{17}$. Some of the mechanisms include a psychodynamic model of primary gain (intended to solve a dilemma, escape an intolerable situation or reduce anxiety), secondary gain (directed to obtain affective or social benefits), a behavioral model of reinforcement of illness behavior (by attention given to symptoms, for instance), and psychosocial model of maladaptive coping responses to stress (due to deficiencies of coping style, for example $)^{17}$. Dissociation, suggestion and hypnotizability mechanisms also act anchored in pathogenic beliefs that suggest to the patient a severe disease. Suggestion and dissociation also is found in the unconscious modeling of symptoms by the patient, based in his personal past experience or in his conceptualization of the medical problem ${ }^{18}$. 


\section{EPIDEMIOLOGY OF PNES}

Studies on the prevalence of PNES show variable but clinically significant results, from five to $33 \%$ of outpatients receiving treatment for epilepsy, and from 10 to $58 \%$ of inpatients treated for refractory epilepsy present $\mathrm{PNES}^{19}$. According to Gates ${ }^{16}$ such a significant difference in results may be explained by differences in diagnostic criteria for PNES. A female preponderance of up to $80 \%$ has been observed in studies of patients with PNES ${ }^{5,16,17,19}$. PNES is present in children and elderly people, but many patients' age range between the 20 's and $30{ }^{\prime 20}$.

\section{IMPACT OF PNES}

PNES is as disabling as epilepsyand may lead to severe social and psychological impairments ${ }^{20}$. Patients are also exposed to iatrogenic procedures, such as high doses of AEDs, intravenous AED use, and orotracheal intubation ${ }^{21}$. Quality of life (QoL) measures in patients with PNES reveal that QoL is worse than that of patients with refractory epilepsyand that QoL is related to symptoms and depression ${ }^{21}$. The diagnostic delay in PNES patients has been reported in the past an average of 7.2 years, however, with increasing awareness of PNES by providers and patients with seizures, and the increased access to seizure monitoring units, the time to correct diagnosis is decreasing, considerably ${ }^{21}$.

\section{CLINICAL PATH TO DIAGNOSIS OF PNES}

The possibility of PNES being present is usually considered when there is a complete absence of therapeutic response to AED, loss of response (therapeutic failure), or paradoxical responses (worsening or spontaneous and unexpected remissions). Likewise, PNES may be considered because of atypical, multiple, inconsistent or changing seizure patterns, or when the seizures are provoked by evident and specific emotional stress, with a narrow temporal relation to seizure occurrence ${ }^{21,22}$. Table 1 summarizes important clinical semiologic features of PNES that help distinguish it from epileptic seizures. These elements are considered

Table 1. Clinical features of psychogenic nonepileptic seizures (PNES).

Long duration

Fluctuating course

Asynchronous movements

Pelvic thrusting

Side-to-side head or body movement

Closed eyes during episode

Ictal crying

Memory recall particularly when the patient demonstrates normal ancillary exams, (interictal routine EEGs, and neuroimaging studies, such as brain CT, MRI and SPECT) ${ }^{22}$. The suspected diagnosis raised by a neurologist has a positive predictive value of $84.6 \%$ for PNES ${ }^{22}$. Patients with PNES tend to have a greater frequency of seizures than do epilepsy patients ${ }^{21,22}$. They also have a greater frequency of hospital admissions due to prolonged seizures, or nonepileptic status ${ }^{21}$. The occurrence of seizures in the physician's office or in the waiting room is very suggestive of PNES, as well as a history of unexplained "chronic pain" or "fibromyalgia" ${ }^{21}$. Antecedent trauma is reported by up to $70 \%$ of PNES patients, and sexual abuse in $40 \%$, which may be an underestimate ${ }^{21,23}$. They also have other psychogenic disorders in approximately $70 \%$ of $\operatorname{cases}^{21,23}$.

\section{DIAGNOSIS DURING VIDEO EEG}

Video EEG (VEEG) is the "gold standard" for proper diagnosis of PNES ${ }^{21,24}$. During VEEG monitoring, behavior and electroencephalographic activity are simultaneously registered. A spontaneous or elicited event is defined as a PNES when there is no ictal EEG evidence of epileptic discharges before, during or after the ictus, and semiology is consistent with PNES and not epilepsy. The event must be critically investigated in the context of clinical data because simple partial epileptic seizures, parietal lobe and hypermotor complex partial frontal lobe epileptic seizures may occur without evident epileptic discharges ${ }^{21,24}$. The International League Against Epilepsy (ILAE) NES Task Force published minimal requirements for NES diagnosis, which utilizes history, semiology and EEG (preferably video) to establish diagnosis $^{25}$. As is done with PMD diagnosis, levels of diagnostic certainty are ranked based on what data are available from history, witnessed event and diagnostic testing, with levels of Possible, Probable, Clinically Established, and Documented diagnosis (see Table 2).

Provocative procedures, such as saline provocation, hypnosis, simple suggestions, suggestive interview or a mixture of them have been used to obtain a typical event, however, the ethics of provocative procedures has been raised ${ }^{24,25}$. The average sensitivity of saline provocation across studies with VEEG monitoring is approximately $74 \%^{24}$. Routine activation procedures (hyperventilation and photic stimulation) can be used during EEG for seizure induction and do not pose the risk of compromising the physician-patient alliance. Approximately $10 \%$ of patients with PNES have epilepsy, when studied using the most stringent criteria $^{26}$. Other reports show a range from 5.3 to $73 \%$ of patients with PNES with mixed epilepsy $y^{5,16,17,18,19,25,26}$. This variability in different studies may reflect several methodological aspects. A study carried in a Brazilian tertiary center found this association occurring in $50 \%$ of PNES patients ${ }^{26}$, a higher association 
Table 2. Overview of proposed diagnostic levels of certainty for psychogenic nonepileptic seizures.

\begin{tabular}{|c|c|c|c|}
\hline & story & Witnessed event (semiology) & and $E E G$ \\
\hline \multicolumn{4}{|l|}{ Diagnostic level } \\
\hline Possible & + & By witness or self-report/description & No epileptiform activity in routine or sleep deprived interictal EEG \\
\hline Probable & + & $\begin{array}{l}\text { By clinician who reviewed video recording or } \\
\text { in person, showing typical semiology of PNES }\end{array}$ & No epileptiform activity in routine or sleep deprived interictal EEG \\
\hline $\begin{array}{l}\text { Clinically } \\
\text { established }\end{array}$ & + & $\begin{array}{l}\text { By clinician experienced in diagnosis of seizure } \\
\text { disorders (on video or in person), showing typical } \\
\text { semiology of PNES, while not on EEG }\end{array}$ & $\begin{array}{c}\text { No epileptiform activity in routine or ambulatory ictal EEG during } \\
\text { a typical ictus/event in which the semiology would make } \\
\text { ictalepileptiform EEG activity expectable during equivalent } \\
\text { epileptic seizures }\end{array}$ \\
\hline Documented & + & $\begin{array}{c}\text { By clinician experienced in diagnosis of seizure } \\
\text { disorders, showing typical semiology of PNES, } \\
\text { while on video EEG }\end{array}$ & $\begin{array}{l}\text { No epileptiform activity immediately before, during or after ictus } \\
\text { captured on ictal Video EEG with typical PNES semiology }\end{array}$ \\
\hline
\end{tabular}

level than found in studies in the US. Comorbid psychiatric disorders are the rule in patients with PNES, however, brief psychiatric consults do not always find clear abnormalities during the mental status examination that are found with more comprehensive anamnesis. Comorbidity with depressive, anxiety and borderline and obsessive compulsive personality disorders is high ${ }^{16,23,27}$. Patients who receive no feedback or intervention after VEEG have no improvement or worsening of $\mathrm{PNES}^{28}$. In contrast, a correct diagnosis or a therapeutic communication can reduce or even abolish PNES in a significant amount of patients, at least temporally ${ }^{28}$, although if no treatment is proposed after communication, seizures may return, or even the appearance of new medically unexplained symptoms ${ }^{20,28}$.

\section{PROGNOSIS OF PNES}

Adults with PNES having risk factors that include comorbid depression, a personality disorder and a history of abuse were more likely to have persistence of seizures, compared to those without these comorbidities ${ }^{28}$. Several studies show that early and correct diagnosis of PNES, followed by adequate treatment, could lead either to remission in 19 to $25 \%$, or to improvement in 75 to $95 \%$. Therefore, correct diagnosis and treatment might result in a significant reduction of utilization and cost of health programs $\mathrm{s}^{20,23,24,28}$.

\section{PSYCHOGENIC MOVEMENT DISORDERS}

Identifying psychogenic movement disorders can be a challenging task in neurological practice. Historically, Charcot was known for his great interest in psychogenic cases and for paying special attention in its definition and treatment ${ }^{2}$. Charcot considered that besides women, men employed in labor, effeminate men and children were prone to the development of hysterical neurological deficits, including PNES (then referred to as hysteroepilepsy) and PMD ${ }^{2,29,30}$.
More recent epidemiological data show that PMD represents $2 \%$ to $3 \%$ of all cases seen in movement disorders clinics and occur more commonly in women (ratio of men to women about 1:5) between 37 and 50 years of age ${ }^{30,31,32,33}$. Like PNES, comorbidities are common in PMD. Ten to $15 \%$ of cases with PMD have additional neurological disorders, and $80 \%$ have psychiatric comorbidities ${ }^{6,731,32,33,34,35,36}$. Other risk factors for PMD include a history of sexual abuse, surgery, trauma and major emotional stress ${ }^{31,33,34}$. Somatoform disorders are very common in PMD, including somatization disorder, conversion disorder, and hypochondriasis, followed by depression, anxiety and personality disorders ${ }^{29,31,33,34}$.

\section{DIAGNOSIS OF PMD}

The semiology and characteristics of PMD are important for the diagnosis. The onset of PMD is usually abrupt and occurs in the context of a precipitating event. Disabilities may be selective, and signs may improve with distraction ${ }^{31,33}$. In general, PMD are not consistent over time and are not congruent with the classical definitions of neurological movement disorders. The association of changes in abnormal movements with distractibility is very common and is an important observation used during examination. Fatigability, particularly in patients presenting with tremor, is also common ${ }^{33,35}$. In some cases, abnormal movements stop when fatigue appears. PMD can present with a wide variety of manifestations, including tremor, dystonia, chorea, gait disorders, parkinsonism, tics and ataxia, usually in combination and affecting multiple body parts. The diagnosis of PMD has been classically viewed as one of exclusion ${ }^{32,33,34,45}$. However, recent clinical advances and advances in neurophysiological examinations have led to the establishment of diagnostic criteria that help clinicians make a more accurate diagnosis and manage the disease better ${ }^{31}$. There are some clinical characteristics of PMD that are more common in clinical neurological practice. Table 3 summarizes the signs and characteristics associated with PMD. PMD 
Table 3. Clinical clues suggesting that movement disorder may be psychogenic.

\begin{tabular}{l} 
Paroxysmal movement disorder \\
Abrupt onset \\
Spontaneous remissions \\
Bizarre movement \\
Movement increase with attention or decrease with distraction \\
Inconsistent movements \\
Incongruous movements \\
Deliberate slowness of movement \\
Association with other functional neurological disorder \\
(functional motor, sensory, gait disorder, and PNE) \\
Response to placebo, suggestion or psychotherapy \\
\hline
\end{tabular}

are traditionally classified into the following four categories according to basic definitions proposed originally by Fahn and Williams in $1988^{36}$ and subsequently modified by Fahn in $1994^{37}$. The same diagnostic level category names are used for PNES, however, the criteria for the diagnostic designation differ significantly for PMD:

(i) Documented PMD: Documented PMD includes those patients who have complete resolution of PMD following psychotherapy, psychological suggestion by the physician, physiotherapy or administration of a placebo with suggestion or are witnessed as being free of symptoms when left alone and supposedly unobserved;

(ii) Clinically established PMD: Clinically established PMD is inconsistent over time or incongruent with the typical presentation of a classical movement disorder. In the presence of either of the above, the patient must have any of the additional manifestations, including other neurological signs, multiple somatizations, obvious psychiatric disturbance, disappearance of the PMD with distraction and excessive (almost deliberate) slowing;

(iii) Probable PMD: Probable PMD includes patients with incongruous and inconsistent movements in the absence of any of the other features listed in category 2 (Clinically established) to support the diagnosis of PMD and patients with a movement disorder that is consistent and congruent with a classical neurological movement disorder but who have other features, such as disappearance of the movement with distraction or other psychogenic neurologic disorders and multiple somatizations;

(iv) Possible PMD: Possible PMD is characterized by clinical features of PMD occurring in the presence of an emotional disturbance ${ }^{36,37}$.

Most of the information used to delineate the currently available diagnostic criteria for PMD come from case series. The three most significant of these series are those described by Lang ${ }^{33}$, including the case series of PMD evaluated by
Table 4. Psychogenic Movement Disorder (PMD) type - HC/ FUPR SERIES.

\begin{tabular}{lc}
\hline PMD & $\mathrm{n}(\%)$ \\
\hline Tremor & $42(50.6)$ \\
Dystonia & $27(32.5)$ \\
Gait disorder & $13(15.6)$ \\
Others & $8(9.6)$ \\
Parkinsonism & $7(8.4)$ \\
Myoclonus & $4(5)$ \\
Cerebellar ataxia & $3(4.16)$ \\
Tics & $0(0)$ \\
Total & $83(100)$ \\
\hline HC/FUPR: Hospital de Clínicas, Universidade Federal doParaná. Others \\
(n=8, 9.6\%) (includes chorea, balism, facial movements, stereotypies, \\
"stiff-person", and bizarre movements).
\end{tabular}

Fahn et al., Jankovic et al., and Lang et al. in which tremor, dystonia, myoclonus and mixed (often bizarre) movement disorders were the most common PMD.

Additionally, in a Brazilian series published in 2010 (Table 4), tremor was the most frequent PMD $(55.6 \%)^{30}$. The second most common PMD semiology was pure dystonia (33.3\%), agreeing with data in the medical literature in which the frequency of this presentation ranges from $15 \%$ to $53 \%^{30,31}$. Parkinsonism and myoclonus PMD were uncommon, each occurring in four patients ${ }^{30}$. Factor et al. studied 28 patients with PMD and found that the most common semiology was tremor (50\%), followed by dystonia, myoclonus and parkinsonism ${ }^{31}$. Distractibility (86\%) and abrupt onset (54\%) were the most common clinical characteristics in this series of patients. Twenty-five percent presented with combined PMD and neurological movement disorder ${ }^{31}$.

In general psychogenic or functional tremor (PT) is the most common psychogenic movement disorder ${ }^{37}$. It can occur in any body part, although the hands and arms are the most frequently involved. More rarely, PT can occur in the head and $\operatorname{legs}^{7,37}$. Of the different clues suggesting tremor may be psychogenic, the most common are distractibility, entrainment (a change in the original tremor frequency to match the frequency of a repetitive task performed in another limb) and the presence of coactivation (the co-contraction sign ${ }^{37}$. In general, PT is thought never to affect the fingers, tongue or face ${ }^{37}$. The dystonia semiology represents the second most common form of $\mathrm{PMD}^{38}$.

In neurological clinical practice the border between functional or psychogenic, dystonia (FD) and neurological dystonia is not clear-cut ${ }^{7,8,37}$. Historically, several forms of dystonia have been considered to be of psychogenic origin, such as blepharospasm and writer's cramp ${ }^{7,8,37}$. In the last 30 years, however, with the great advances in genetics, neurophysiology and neuroimaging, the phenotypes of primary idiopathic dystonia have been clearly defined. Some forms of fixed dystonia associated with previous peripheral trauma and with pain similar to chronic regional pain syndrome ("causalgia-dystonia"), have been considered $\mathrm{FD}^{7.8}$. The most 
common forms of FD are blepharospasm, limb focal dystonia and abductor laryngeal dystonia or paradoxical vocal cord dysfunction ${ }^{33,35,36,37,38}$.

The next most common form of PMD is myoclonus, now defined as functional myoclonus $(\mathrm{FM})^{39}$. In this setting, electrophysiological tests are needed to ensure correct diagnosis, particularly those using electroencephalogram-electromyography back-averaging ${ }^{39}$. Functional parkinsonism, chorea, tics and ataxia are rarely reported ${ }^{40}$.

\section{Prognosis OF PMD}

Patients with PMD usually have a poor prognosis ${ }^{41,42}$. Cases with at least six months of symptoms at the time of diagnosis had little or no response to proposed treatments ${ }^{41,42}$. Feinstein et al. ${ }^{43}$, after evaluating psychiatric outcomes of their patients with a mean follow up of 3.2 years, showed that PMD persisted in more than $90 \%$ of them, especially in cases with comorbid major depression, anxiety and personality disorders ${ }^{43}$. In contrast, Thomas et al., evaluated 228 patients with PMD with a mean follow-up of 3.4 years (6 months to 12 years), and concluded that symptoms improved in $56.6 \%$ of patients, worsened in $22.1 \%$ and remained the same in $21.3 \%^{42}$. Ertan et al. studied 49 patients with PMD in a tertiary clinic in Turkey and concluded that the response to treatment was poor, with a high rate of drop out of these patients in the follow-up ${ }^{44}$.

\section{PSYCHOGENIC MOVEMENT DISORDERS AND NON- EPILEPTIC SEIZURES}

An intriguing question is whether PMD and PNES share the same psychopathological comorbidities, particularly anxiety, depression and other conditions, such as personality disorders and trauma/abuse histories ${ }^{45,46,47,48}$. Against this background, Grimaldi et al. performed a prospective comparative study in which they investigated the presence of anxiety and depression in 17 patients, nine of whom had PMD and eight PNES ${ }^{45}$. They concluded that all the patients had the same demographic and psychopathological profile, although in the group with PNES there was a greater incidence of anxiety disorders and a family history of epilepsy ${ }^{45}$. Driver-Dunckley et al. studied 172 patients in a retrospective chart review, comparing 116 patients with PNES with 56 with $\mathrm{PMD}^{46}$. They found that $82 \%$ of the patients were female and that $70 \%$ had chronic pain, $55 \%$ subjective cognitive complaints, $47 \%$ fatigue and $45 \%$ a history of childhood abuse. The patients with PNES had coexisting epilepsy in $17 \%$ of cases, and those with PMD had coexisting neurologic movement disorders in 9\%. The authors concluded that PNES and PMD had the same psychopathology, with more similarities than differences ${ }^{46}$. Hopp et al., studied 104 patients with PMD and 35 with PNES using different cognitive, psychological and social function measures ${ }^{47}$. They demonstrated that patients with PNES and PMD, despite differences in their phenomenology and demographics, shared the same psychiatric symptoms, suggesting that PNES and PMD represent different presentations of a single disorder ${ }^{47}$. Mula published an editorial about PNES and PMD discussing the commonalities between these two conditions ${ }^{48}$. He suggested that these disorders occupy a gray area between neurology and psychiatry and commented on the poor level of integration between neurologists and psychiatrists ${ }^{48}$.

\section{CONCLUDING REMARKS}

Moving the field forward for better understanding of PMD, PNES and other somatoform disorders will require increased collaboration between neurology and psychiatry. A renaissance of neuropsychiatry is being driven by advances in functional neuroimaging, neuroscience and the treatment needs of the aging population with neurodegenerative neuropsychiatric disorders. Viewing somatoform/conversion disorders from a combined lens of neurology/psychiatry provides a comprehensive assessment approach and opens avenues of collaborative management.

\section{"Lumpers or Splitters"}

From prior research the question arises, should PMD and PNES be "lumped or split", that is, are they "variations on a theme", or independent populations? Larger samples for fully powered designed studies may require incorporating both PMD and PNES. On the other hand, discrete samples may be needed to identify regions of interest and putative networks in biomarker focused studies. Also of note is that a number of patients with PNES also have other movement symptoms without change in level of consciousness, apart from their ictus, possibly generating a third group of "mixed PNES/PMD". These issues can be addressed by linking research centers to reach target sample sizes.

\section{Treatment of PNES and PMD}

Great strides have been made in validating treatment for patients with PNES in the past decade. Prior to the NINDS/ NIMH/AES supported NES Workshop in 2005, only class III and IV level treatment data existed ${ }^{24,49}$. The NES workshop set the NES research benchmarks, and PNES treatment is a target of the NINDS Epilepsy Research Benchmarks ${ }^{49}$. Our group and others have been systematically developing treatments for patients with PNES and studying biomarkers of PNES. This is being accomplished through multi-disciplinary, multi-modal, multi-site work. Examples of advances in PNES treatment over the last decade include examining clinical trial methodology in PNES in an open label study of sertraline for $\mathrm{PNES}^{49}$, followed by a pilot placebo-controlled 
RCT with sertraline ${ }^{49}$. Standard medical care (SMC) or treatment as usual (TAU) is in the US,and in a cross-cultural comparison with Chile has been described ${ }^{50}$. A psychotherapy initially used in epilepsy has been modified for PNES and was used to conduct an open label trial for PNES ${ }^{51}$. With pharmacologic, psychotherapeutic and SMC data, a multicentered, RCT comparing PNES-CBT, sertraline, PNES-CBT and sertraline, and SMC/TAU was conducted ${ }^{52}$. Based on the successful reduction in seizures, improvement in comorbidities, QoL and functioning in the two groups treated with the manualized therapy, the treatment workbook ${ }^{53}$ is being published along with a therapist's guide ${ }^{54}$. Providers at sites across the US are being trained in administering the manualized treatment. These and other modalities studied in PNES treatments are reviewed in the ILAE NES management article $^{55}$. Advances in PMD treatment include an open label trial of sertraline for $\mathrm{PMD}^{56}$. In another study, psychodynamic psychotherapy was used in a single-blind treatment trial for patients with $\mathrm{PMD}^{56}$. Non-psychotherapy modalities including physiotherapy also have been used to treat patients with $\mathrm{PMD}^{57}$. A summary of cognitive behavioral approaches used in patients with funtional neurololgical disorders provides a review of studies in a variety of somatoform presentations ${ }^{58}$.
With the momentum of recognition by the Movement Disorders Society (MDS) and the International League Against Epilepsy (ILAE)designating these populations' symptoms as significant disorders found in patients with movement disorders and seizures, task forces are setting standards for diagnosis and treatment. Examples include the ILAE NES Task Force establishing the minimum requirements standards for making the diagnosis of PNES ${ }^{25}$, and summarized the literature on PNES management ${ }^{55}$. Text books are published summarizing the NES ${ }^{59}$, and PMD literature $^{60}$. National research funding sources (Institutes, Medical Societies and voluntaries) now are providing support for studies examining treatment and mechanisms for patients with conversion disorders. With greater identification of the somatoform disorders by neurologists, psychiatrists, primary care physicians, opportunities for treatment are opened. With a neuropsychiatric conceptualization and formulation and with more management options now available, this population is being demystified and providers are empowered to effectively treat patients. Cross-disciplinary and cross-cultural collaboration will continue to facilitate advances in this common and challenging neuropsychiatric disorder.

\section{References}

1. Edwards M. Historical keyword: hysteria [editorial]. Lancet 2009(9702);374:1669. http://dx.doi.org/10.1016/S0140-6736(09)61979-6

2. Goetz CG, Bonduelle M, Gelfand T. Hysteria. In: Goetz CG, Bonduelle M, Gelfand T. Charcot. Constructing neurology. New York: Oxford University Press; 1995. p. 172-216.

3. Linden SC, Jones E, Lees AJ. Shell shock at queen square: Lewis Yealland 100 years on. Brain. 2013;136(Pt 6):1976-88. http://dx.doi. org/10.1093/brain/aws331

4. Stone J, Warlow C, Carson A, Sharpe M. Eliot Slater's Myth of the non-existence of hysteria. J R Soc Med. 2006;98(12):547-8. http://dx.doi.org/10.1258/jrsm.98.12.547

5. Rowan AJ. An introduction to current practice in the diagnosis of non-epileptic seizures. In: Gates JR, Rowan AJ. Non-epileptic seizures. Boston: Butteworth-Heinemann; 1993. p. 1-8.

6. Hinson VK, Haren WB. Psychogenic movement disorders. Lancet Neurol. 2006;5(8):695-700. http://dx.doi.org/10.1016/S1474-4422(06) 70523-3

7. Edwards MJ, Bhatia KP. Functional (psychogenic movement disorders: merging mind and brain. Lancet Neurol. 2012;11(3):250-60. http://dx.doi.org/10.1016/S1474-4422(11)70310-6

8. Lempert T, Dietrich M, Huppert D, Brandt T. Psychogenic disorders in neurology: frequency and clinical spectrum. Acta Neurol Scand. 1990;82(5):335-40. http://dx.doi.org/10.1111/j.1600-0404.1990. tb03312.x

9. Stone J, LaFrance Jr WC, Levenson JL, Sharpe M. Issues for DSM-V: conversion disorder. Am J Psychiatry. 2010;167(6):626-7. http://dx.doi.org/10.1176/appi.ajp.2010.09101440

10. American Psychiatric Association. Diagnostic and statistical manual of mental disorders. 5th ed. (DSM-V). Arlington: American Psychiatry Publishing; 2013.

11. Daum C, Hubschmid M, Aybek S. The value of "positive" clinical signs for weakness, sensory and gait disorders in conversion disorder: a systematic and narrative review. J Neurol Neurosurg Psychiatry. 2014;85(2):180-90. http://dx.doi.org/10.1136/jnnp-2012-304607

12. Lombardi TL, Barton E, Wang J, Eliashiv DS, Chung JM, Muthukumaran A et al. The elbow flex-ex: a new sign to detect unilateral upper extremity non-organic paresis. J Neurol Neurosurg Psychiatry. 2014;85(2):165-7. http://dx.doi.org/10.1136/jnnp-2012-304607

13. Rowe JB. Conversion disorder: understanding the pathogenic links between emotion and motor systems in the brain. Brain. 2010;133(Pt 5):1295-9. http://dx.doi.org/10.1093/brain/awq096

14. Stone J, Carson A, Duncan R, Coleman R, Roberts R, Warlow C et al. Symptoms "unexplained by organic disease" in 1144 new neurology out-patients: how often does the diagnosis change at follow-up? Brain. 2009;132(Pt 10):2878-88. http://dx.doi.org/10.1093/brain/awp220

15. Hurwitz TA, Prichard JW. Conversion disorder and fMRI. Neurology. 2006;67(11):1914-815. http://dx.doi.org/10.1212/01.wnl.0000249127. 69348.a4

16. Gates JR. Epidemiology and classification of non-epileptic events. In: Gates JR, Rowan AJ, editors. Non-epileptic seizures. 2th ed. Boston: Butterworth-Heinemann; 2000. p. 3-14.

17. LaFrance Jr, WC, Bjornaes, H. Designing treatment plans based on etiology of psychogenic nonepileptic seizures. In: Schachter, SC, LaFrance Jr, WC, editors. Gates \& Rowan's Nonepileptic seizures. 3 rd ed. New York: Cambridge University Press; 2010. p. 266-80.

18. Marchetti RL, Kurcgant D, Gallucci Neto J, Bismark MA, Marchetti LB, Fiore LA. Psychiatric diagnoses of patients with psychogenic non-epileptic seizures. Seizure. 2008;17(3):247-53. http://dx.doi.org/ 10.1016/j.seizure.2007.07.006

19. Benbadis SR, Hauser AW. An estimate of the prevalence of psychogenic non-epileptic seizures. Seizures 2000;9(4):280-1. http://dx.doi.org/10.1053/seiz.2000.0409

20. Reuber M, Pukrop R, Bauer J, Helmstaedter C, Tessendorf N, Elger CE. Outcome in psychogenic nonepileptic seizures: 1 to 10 -year 
follow-up in 164 patients. Ann Neurol. 2003;53(3):305-11. http://dx. doi.org/10.1002/ana.3000

21. Brown RJ, Syed TU, Benbadis S, LaFrance WC Jr, Reuber M. Psychogenic nonepileptic seizures. Epilepsy Behav. 2011;22(1):85-93. http://dx.doi.org/10.1016/j.yebeh.2011.02.016

22. Avbersek A, Sisodiya S. Does the primary literature provide support for clinical signs used to distinguish psychogenic nonepileptic seizures from epileptic seizures? J Neurol Neurosurg. 2010;81(7):719-25. http://dx.doi.org/10.1136/jnnp.2009.197996

23. Proença IC, Castro LH, Jorge CL, Marchetti RL. Emotional trauma and abuse in patients with psychogenic nonepileptic seizures. Epilepsy Behav. 2011;20(2):331-3. http://dx.doi.org/10.1016/j.yebeh. 2010.11.015

24. LaFrance JrWC, Devinsky O. The treatment of psychogenic nonepileptic seizures: historical perspectives and future directions. Epilepsia. 2004;45(Suppl. s2):15-21. http://dx.doi.org/10.1111/j.0013-9580.2004. 452002.x

25. LaFrance Jr WC, Baker GA, Duncan R, Goldstein LH, Reuber M. Minimum requirements for the diagnosis of psychogenic nonepileptic seizures: a staged approach: A report from the International League Against Epilepsy Nonepileptic Seizures Task Force. Epilepsia. 2013;54(11):2005-18. http://dx.doi.org/10.1111/epi.12356

26. Marchetti RL, Kurcgant D, Gallucci Neto J, Von Bismark MA, Fiore LA. Epilepsy in patients with psychogenic non-epileptic seizures. Arq Neuropsiquiatr. 2010;68:168-73. http://dx.doi.org/10.1590/s0004$282 \times 2010000200003$

27. Martin R, Burneo JG, Prasad A, Powell T, Faught E, Knowlton R et al. Frequency of epilepsy in patients with psychogenic seizures monitored by video-EEG. Neurology. 2003;61(12):1791-2. http://dx.doi.org/10.1212/01.wnl.0000098890.13946.f5

28. Fiszman A, Kanner AM. Comorbidities in psychogenic nonepileptic seizures: Depressive, anxiety, and personality disorders. In: Schacter S, LaFrance Jr WC, editors. Gates and Rowan's Nonepileptic seizures. 3rd ed. Cambridge: Cambridge University Press; 2010. p. 225-34.

29. Goetz CG. Charcot and psychogenic movement disorders. In: Hallet M, Fahn S, Jankovic J, Lang AE, Cloninger CR, Yudofsky SC. Psychogenic movement disorders: neurology and neuropsichiatry. Philadelphia: Lippincot Williams \& Wilkins; 2006. p. 3-13.

30. Munhoz RP, Zavala JA, Becker N, Teive HAG. Cross-cultural influences on psychogenic movement disorders: a comparative review with a Brazilian series of 83 cases. Clinical Neurol Neurosurg. 2011;113(2):115-8. http://dx.doi.org/10.1016/j.clineuro.2010.10.004

31. Factor SA, Podskalny GD, Molho ES. Psychogenic movement disorders frequency, clinical profile and characteristics. J Neurol Neurosurg Psychiatry. 1995;59(4):406-12. http://dx.doi.org/10.1136/ jnnp.59.4.406

32. Galvéz-Jimenez N, Lang AE. Psychogenic movement disorders. In: Watts RL, Koller WC. Movement disorders: neurologic principles and practice. New York: McGraw-Hill; 1997. p. 715-32.

33. Lang AE. General overview of psychogenic movement disorders: epidemiology, diagnosis, and prognosis. In: Hallet M, Fahn S, Jankovic J, Lang AE, Cloninger CR, Yudofsky SC. Psychogenic movement disorders: neurology and neuropsichiatry. Philadelphia: Lippincot Williams \& Wilkins; 2006. p. 35-41.

34. Williams DT, Ford B, Fahn S. Phenomenology and psychopathology related to psychogenic movement disorders. Adv Neurol. 1995;65:231-57. http://dx.doi.org/10.1002/9781444346183.ch24

35. Gupta A, Lang AE. Psychogenic movement disorders. Curr Opin Neurol. 2009;22(4):430-6. http://dx.doi.org/10.1097/WCO. Ob013e32832dc169

36. Fahn S, Williams D. Psychogenic dystonia. Adv Neurol. 1988;50:431-55.

37. Bhatia KP, Schneider SA. Psychogenic tremor and related disorders. $J$ Neurol. 2007;254(5):569-74. http://dx.doi.org/10.1007/s00415-006$0348-z$
38. Lang AE. Psychogenic dystonia: a review of 18 cases. Can J Neurol Sci. 1995;22(2):136-43.

39. Monday K, Jankovic J. Psychogenic myoclonus. Neurology 1993;43(2):349-52. http://dx.doi.org/10.1212/wnl.43.2.349

40. Lang AE, Koller WC, Fahn S. Psychogenic parkinsonism. Arch Neurol. 1995;52(8):802-10. http://dx.doi.org/10.1001/archneur.1995. 00540320078015

41. Lang AE. Long term follow-up of psychogenic movement disorders. Neurology. 2000;54(Suppl 3):A50-1.

42. Thomas $M$, Vuong KD, Jankovic J. Long-term prognosis with psychogenic movement disorders. Parkinsonism Related Disord. 2006;12(6):382-7. http://dx.doi.org/10.1016/j.parkreldis.2006.03.005

43. Feinstein A, Stergiopoulos V, Fine J, Lang AE. Psychiatric outcome in patients with a psychogenic movement disorder: a prospective study. Neuropsychiatry Neuropsychol Behav Neurol. 2001;14(3):169-76.

44. Ertan S, Uluduz D, Ozekmekçi S, Kiziltan G, Ertan T, Yalçinkaya C et al. Clinical characteristics of 49 patients with psychogenic movement disorders in a tertiary clinic in Turkey. Mov Disord. 2009;24(5):759-82. http://dx.doi.org/10.1002/mds.22114

45. Grimald I, Dubuc M, Kahane P, Bougerol T, Vercueil L. Anxiety and depression in psychogenic movement disorder and non-epileptic seizures: a prospective comparative study. Revue Neurol (Paris). 2010;166(5):515-22. http://dx.doi.org/10.1016/j.neurol.2009.10.016

46. Driver-Dunckley E, Stonnington CM, Locke DEC, Noe K. Comparison of psychogenic movement disorders and psychogenic nonepileptic seizures: Is phenotype clinically important? Psychosomatics. 2011;52(4):337-45. http://dx.doi.org/10.1016/j.psym.2011.01.008

47. Hopp JL, Anderson KE, Krumholz A, Gruber-Baldini AL, Shulman LM Psychogenic seizures and psychogenic movement disorders: are they the same patients? Epilepsy Behav. 2012;25(4):666-9. http://dx.doi. org/10.1016/j.yebeh.2012.10.007

48. Mula M. Are psychogenic non-epileptic seizures and psychogenic movement disorders two different entities? When even neurologists stop talking to each other. Epilepsy Behav. 2013;26(1):100-1. http://dx.doi.org/10.1016/j.yebeh.2012.07.024

49. LaFrance WC Jr, Alper K, Babcock D, Barry JJ, Benbadis S, Caplan R et al. Nonepileptic seizures treatment workshop summary. Epilepsy Behav. 2006;8(3):451-61. http://dx.doi.org/10.1016/j.yebeh.2006.02.004

50. LaFrance WC Jr, Marinis AJ, Webb AF, Machan JT, Rusch MD, Kanner AM. Comparing standard medical care for nonepileptic seizures in Chile and the United States. Epilepsy Behav. 2012;25(2):224-29. http://dx.doi.org/10.1016/j.yebeh.2012.07.028

51. LaFrance WC Jr, Miller IW, Ryan CE, Blum AS, Solomon DA, Kelley JE et al. Cognitive behavioral therapy for psychogenic nonepileptic seizures. Epilepsy Behav. 2009;14(4):591-6. http://dx.doi.org/10.1016/j. yebeh.2009.02.016

52. LaFrance WC Jr, Baird GB, Barry JJ, Blum AS, Webb FA, Keitner GL et al. Multicenter pilot preatment trial for psychogenic nonepileptic seizures. JAMA Psychiatry. 2014;71(9):997-1005. http://dx.doi.org/ 10.1001/jamapsychiatry.2014.817

53. Reiter J, Andrews D, Reiter C, LaFrance WC Jr. Taking control of your seizures: a Workbook. New York: Oxford University Press; 2014.

54. LaFrance WC, Wincze J. Taking control of your seizures: therapist guide. New York: Oxford University Press; 2014.

55. LaFrance WC, Reuber M, Goldstein LH. Management of psychogenic nonepileptic seizures. Epilepsia. 2013;54 Suppl 1:S53-67. http://dx.doi.org/10.1111/epi.12106

56. Hinson VK, Weinstein S, Bernard B, Leurgans SE, Goetz CG. Singleblind clinical trial of psychotherapy for treatment of psychogenic movement disorders. Parkinsonism Relat Disord. 2006;1(3)2:177-80. http://dx.doi.org/10.1016/j.parkreldis.2005.10.006

57. Czarnecki K, Thompson JM, Seime R, Geda YE, Duffy JR, Ahlskog JE. Functional movement disorders: successful treatment with a 
physical therapy rehabilitation protocol. Parkinsonism Relat Disord. 2012;18:247-51. http://dx.doi.org/10.1016/j.parkreldis.2011.10.011

58. Hopp JL, LaFrance WC. Cognitive behavioral therapy for psychogenic neurological disorders. Neurologist. 2012;18(6):364-72. http://dx.doi. org/10.1097/NRL.0b013e31826e8ff5
59. Schachter SC, LaFrance WC Jr, editors. Gates and Rowan's Nonepileptic seizures. 3rd ed. Cambridge: Cambridge University Press; 2010.

60. Hallett M, Lang AE, Jankovic J, et al. Psychogenic movement disorders and other conversion disorders. 2nd ed. Cambridge: Cambridge University Press; 2011. 